\title{
Central vein stenosis masquerading as venous thrombosis
}

\author{
Nagapriya Vellalacheruvu, ${ }^{1}$ Naresh Monigari, ${ }^{1}$ Tom Devasia, ${ }^{2}$ Hashir Kareem ${ }^{2}$
}

${ }^{1}$ Department of Medicine, Kasturba Medical College, Manipal, Karnataka, India ${ }^{2}$ Department of Cardiology, Kasturba Medical College, Manipal, Karnataka, India

\section{Correspondence to}

Dr Naresh Monigari, medico.ktya@gmail.com

Accepted 5 March 2014

CrossMark

To cite: Vellalacheruvu $N$, Monigari N, Devasia T, et al. BMJ Case Rep Published online: [please include Day Month Year] doi:10.1136/ bcr-2014-203690

\section{DESCRIPTION}

We present a 50-year-old man, a known case of chronic kidney disease stage 5 on maintenance haemodialysis (HD), who presented with acute onset swelling, redness, tenderness of the right arm and venous distension of the right side of the neck. The patient had a history of right internal jugular venous dialysis catheter insertions for $\mathrm{HD}$ and his symptoms started 1 month after starting dialysis with right brachiocephalic fistula access. In view of

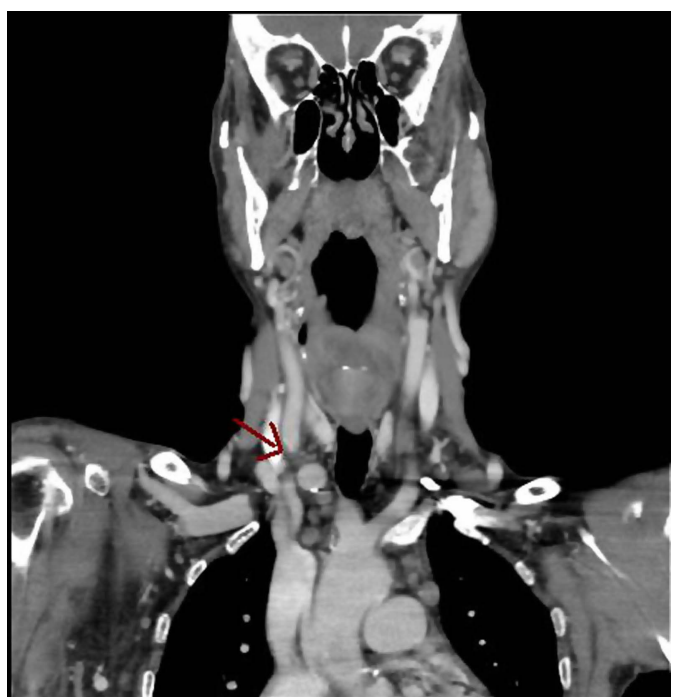

Figure $1 \mathrm{CT}$ venography showing tight stenosis of the right subclavian and right internal jugular veins at confluence.

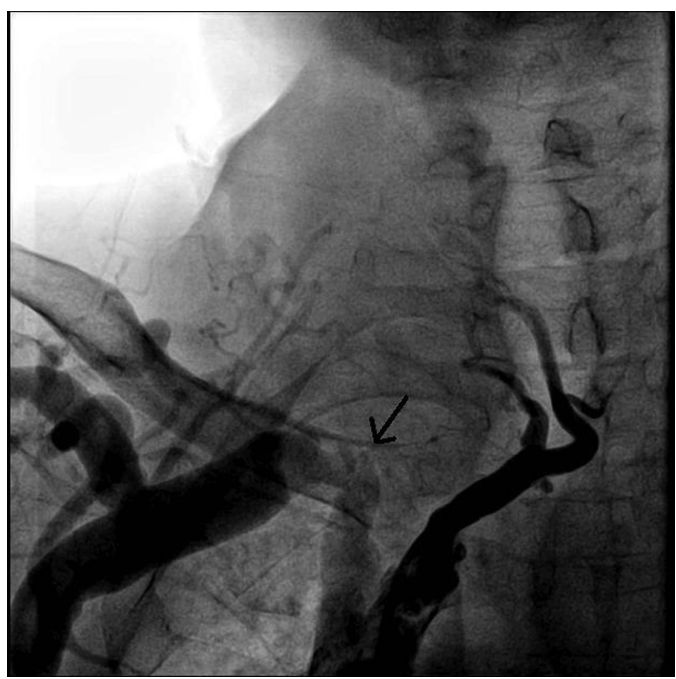

Figure 2 Venous angiography showing discrete tubular stenosis of the right subclavian and right internal jugular veins at confluence. the acute onset of symptoms, a possibility of deep vein thrombosis of the right upper limb or central venous stenosis (CVS) was considered. CVS in patients on $\mathrm{HD}$, although rare, is a known entity. In all patients with acute symptoms, a possibility of thrombosis has to be ruled out as it requires immediate anticoagulation. CT venography coronal views showed tight stenosis of the right internal jugular vein and right subclavian vein at the confluence with normal contrast opacification in the right

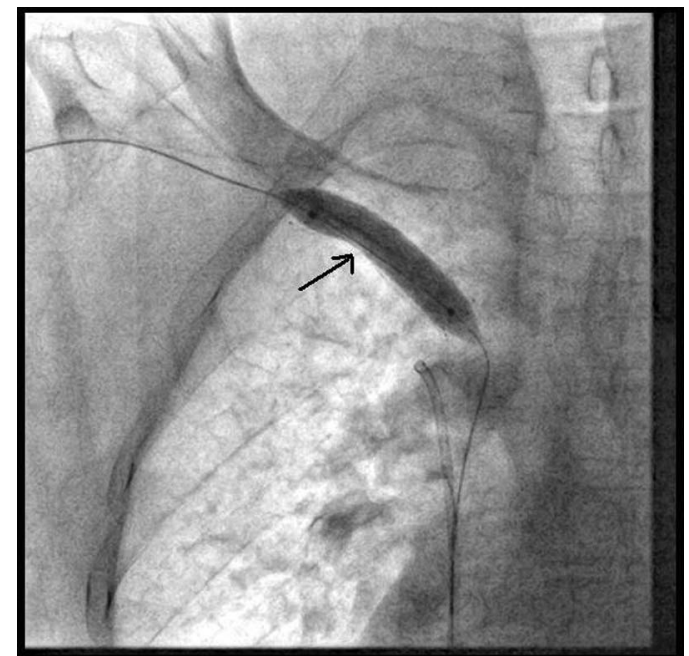

Figure 3 Angioplasty balloon in situ.

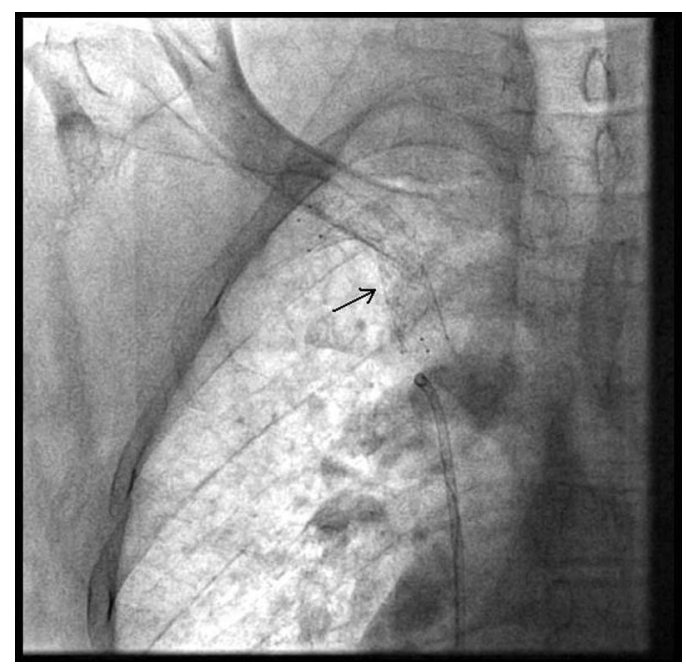

Figure 4 Subclavian vein stent in situ. 


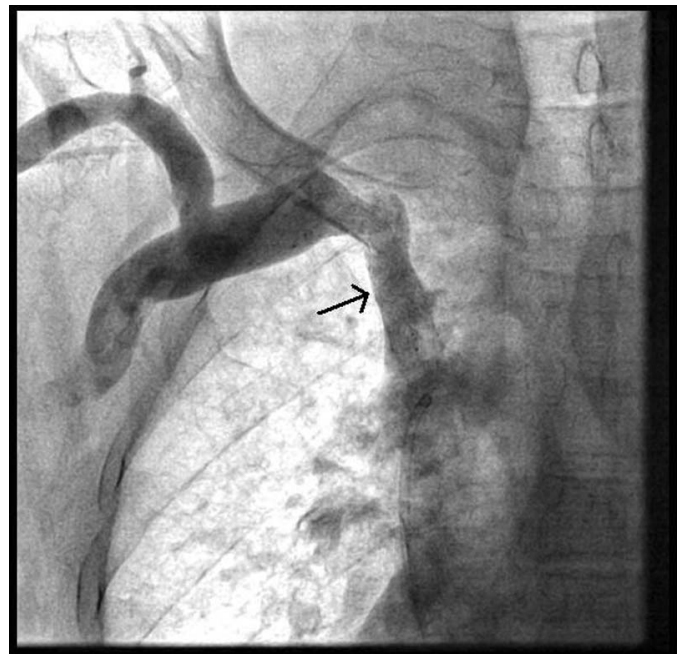

Figure 5 Post stent insertion showing good flow across the stent.

brachiocephalic vein and superior vena cava (SVC) (figure 1), further confirmed by venous angiography (figure 2 ). We postulate that the patient might have had stenosis previously, which was asymptomatic but became symptomatic after arteriovenous fistula (AVF) formation because of the high flow. ${ }^{1}$ Injury to the endothelium of the vascular wall adjacent to the catheter appears to be the most plausible mechanism for CVS, ${ }^{2}$ which further gets exacerbated with high-flow resultant form AVF. ${ }^{1}$ Balloon dilation (figure 3) and stenting (figure 4) with post dilation of the right subclavian vein was performed by vascular access through the fistulised right cephalic vein. Good flow was achieved post stenting (figure 5). Post stent placement, the patient's symptoms improved and the swelling subsided. Balloon dilation with endovascular stenting provides temporary relief but usually requires multiple procedures in the long term. ${ }^{3}$

\section{Learning points}

- Central venous stenosis (CVS), although rare, is a known complication in patients requiring maintenance haemodialysis but symptomatic CVS requiring intervention is not common. ${ }^{1}$

- Symptomatic CVS has to be treated with balloon dilation and percutaneous angioplasty to restore flow and further continuation of arteriovenous fistula (AVF) access. Further studies are required to evaluate the efficacy of stents to provide a symptom-free period.

- Venous mapping and creation of AVF have to be considered in patients with chronic kidney disease requiring maintenance haemodialysis as the occurrence of CVS precludes AVF formation.

Contributors TD and HK performed the balloon dilation and stenting procedure. NM and NV wrote the manuscript and reviewed it before submission.

\section{Competing interests None.}

Patient consent Obtained.

Provenance and peer review Not commissioned; externally peer reviewed.

\section{REFERENCES}

1 Agarwal AK, Patel BM, Haddad NJ. Central vein stenosis: a nephrologist's perspective. Semin Dial 2007;20:53-62.

2 Forauer AR, Theoharis C. Histologic changes in the human vein wall adjacent to indwelling central venous catheters. J Vasc Interv Radiol 2003;14(9 Pt1):1163-8.

3 Sprouse LR II, Lesar CJ, Meier GH III, et al. Percutaneous treatment of symptomatic central venous stenosis [corrected]. J Vasc Surg 2004;39:578-82.

Copyright 2014 BMJ Publishing Group. All rights reserved. For permission to reuse any of this content visit

http://group.bmj.com/group/rights-licensing/permissions.

BMJ Case Report Fellows may re-use this article for personal use and teaching without any further permission.

Become a Fellow of BMJ Case Reports today and you can:

- Submit as many cases as you like

- Enjoy fast sympathetic peer review and rapid publication of accepted articles

- Access all the published articles

- Re-use any of the published material for personal use and teaching without further permission

For information on Institutional Fellowships contact consortiasales@bmjgroup.com

Visit casereports.bmj.com for more articles like this and to become a Fellow 